\title{
Hydatid cyst of soft parts
}

\begin{abstract}
The hydatid cyst is a cosmopolitan parasitic infestation affecting humans and some mammals, related to the development in the body of the larval or hydatid form of a dog's tenia called Echinococcus granulosus. It's a problem of public health in our country and in the breeding areas of developing countries. Muscle localization is rare and unusual even in endemic countries, and it is most often isolated. Through this work, we present a retrospective study of a series of 08 cases of soft parts hydatid cyst observed in department of osteo articular surgery 2, Hassan II university hospital of Fez-Morocco, over a period of five years. The objective of this study is the analysis of epidemiological, clinical, biological, radiological and therapeutic aspects of this disease. The preferred field is that of young person (the average age is 39 years), from rural environment.
\end{abstract}

The predilection was at thigh muscles 7 out of $8(87,5 \%), 4$ at in the adductor compartment. The clinical symptomatology is not specific, represented in the majority of cases by a painless muscular welling fixed to the deep plane, without inflammatory signs, evolving slowly and without alteration of condition. This latency was estimated at 24,4 months in our series. Imaging is essential in the positive diagnosis of muscular hydtidosis, ultrasound is the first line examination for diagnosis, and the MRI allows to better specify the seat of cyst and its reports. All patients underwent a total parikystecomy without medical treatment with a good evolution. Prophylaxis is the best way to control this parasites is in endemic areas.

Keywords: echinococcosis, hydatid cyst, soft tissue, diagnosis and treatment
Volume 4 Issue 6 - 2019

\section{Bensassi Achraf, El Ghadraoui Redouane, Abid hatim, Mohammed El idrissi,Abdelhalim Elibrahimi,Abdelmajid Elmrini \\ Department of Osteo-articular Surgery B4, Hassan II CHU, University Sidi Mohammed Ben Abdellah of Fez, Morocco}

Correspondence: Bensassi Achraf, Osteo-articular Surgery Department B4, Hassan II University Hospital, Sidi Mohammed Ben Abdellah University, 30000 Fez, Morocco, Email bensassi.achraf21@gmail.com

Received: December 12, 2019 | Published: December 23, 2019

\section{Introduction}

The hydatid cyst has been known since antiquity, since Hippocrates said that when the liver is full of water, the patient dies. ${ }^{1,2}$ Hydatidosis is a cosmopolitan anthropozoonosis due to human tissue development of the larva or hydatid of Taenia Echinococcus granulosus, it is endemic in many parts of the world especially in Latin America from Nicaragua to Argentina. including Morocco and constitutes a real public health problem., The parasite evolves only in larval form and is localized preferentially in the liver tissue (60\%), more rarely pulmonary (30\%). Soft tissue localization remains rare even in endemic countries where its frequency is estimated at less than $3 \%{ }^{5,6}$ This primitive and isolated parasitosis continues to pose a public health problem. Hydatid cysts of the soft tissues remain rare, even in endemic countries, where their frequency is estimated at nearly $3 \%$. Their often asymptomatic nature and their slow evolution make their diagnosis late. The diagnosis is based on interrogation, clinical and imaging data. The treatment is essentially surgical; Prophylaxis is the real treatment that must act at all levels of the epidemiological chain. ${ }^{7}$

\section{Material and methods}

Through this work, we present a retrospective study of a series of 08 soft tissue hydatid cyst cases observed in orthopedic trauma department 2 at CHU Hassan II over a period of five years. The objective of this study is the analysis of epidemiological, clinical, biological, radiological, and therapeutic aspects of this condition.

\section{Results}

The average age of our patients was 39.25 years, with extreme ages of 21 and 64 years old. Our series includes a clear predominance of women: 6 women or $75 \%$ of patients versus only 2 men (Figure 1).

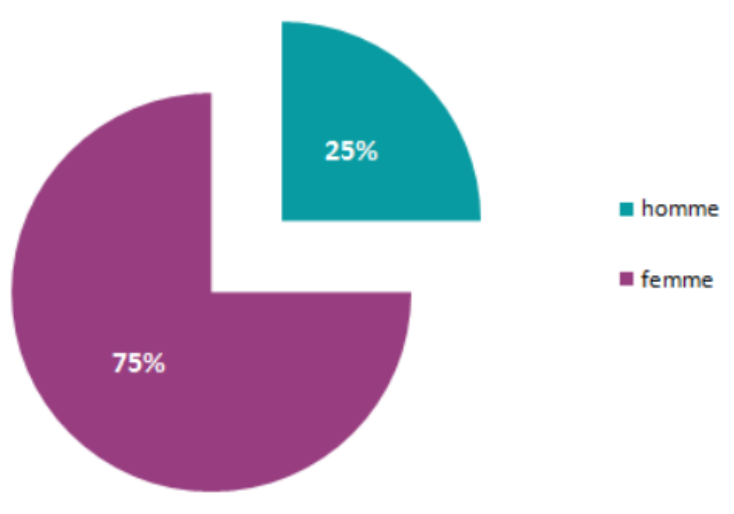

Figure I Distribution of patients by gender.

In our series we note the high prevalence of patients from rural areas with a rate of $75 \%$ while those from the urban area have only $25 \%$ (Figure 2).

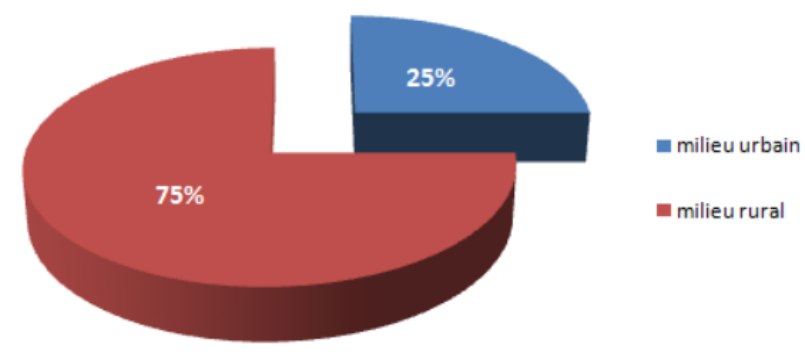

Figure 2 Distribution of patients by geographic origin. 
The localization at the level of the lower limb was dominant with a rate of $87.5 \%$ more particularly at the adductor box (50\%) (Figures 3 ) (Figure 4).75\% of our patients have the notion of contact with dogs, a single patient with an operated hydatid cyst history who recurred after 3 years in the same region.

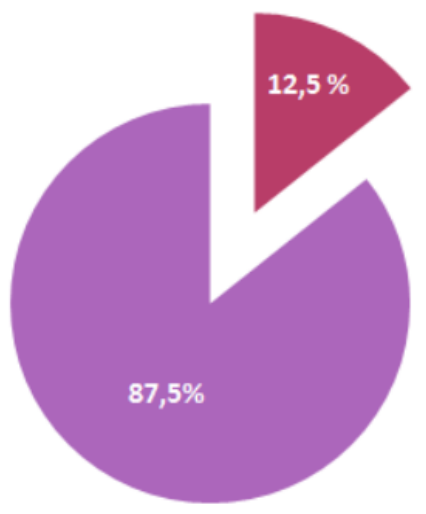

nembre supérieur nembre inférieur

Figure 3 Topography of $\mathrm{KH}$ in our series.

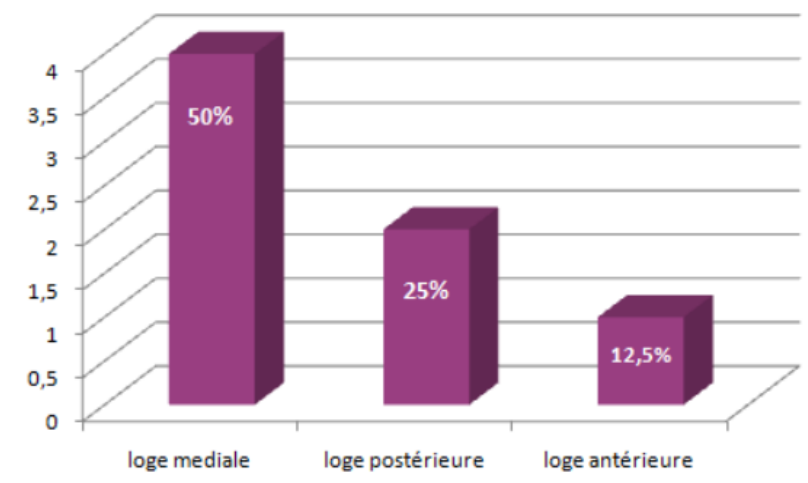

Figure 4 Topography of $\mathrm{KH}$ at the level of the lower limb.

The most common reason for consultation that prompted all our patients to consult is the appearance of soft-tissue swelling of slow evolution ; this latency is estimated at 24.4 months with extremes between 3 months and 5 years ; pain monitoring in two patients and functional gene in a single patient (Figure 5).

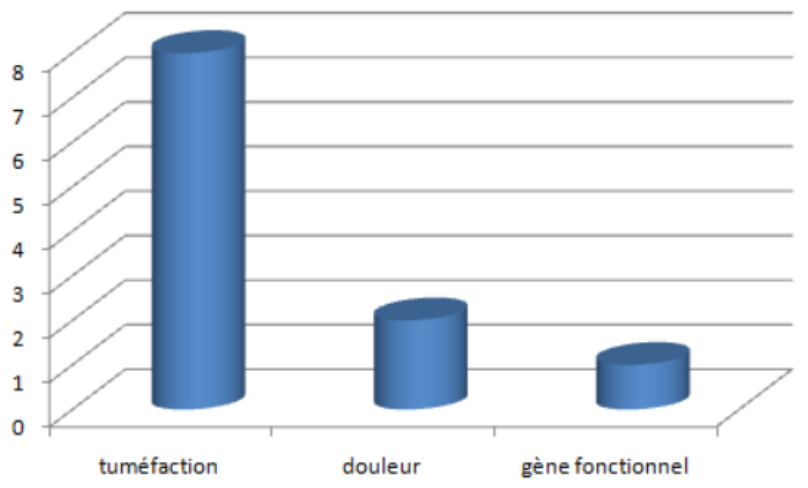

Figure 5 Distribution of patients according to the reason for consultation.
All patients in our series were feverous, hemodynamically and respiratory stable with a conserved general state.

Examination of the musculoskeletal system demonstrated in all our patients the presence of swelling without inflammatory signs compared to free ganglion areas.

Vasculoneural examination was unremarkable in all patients A blood count was performed in all our patients demonstrating hyper eosinophilia in 2 patients only, estimated at $4.5 \%$ (390 elements $\left./ \mathrm{mm}^{3}\right)$ for the first and $5.2 \%$ or 475 elements $/ \mathrm{mm}^{3}$ for the second.

An inflammatory assessment based on VS and CPR is done in most of our patients showing a VS at $22 \mathrm{~mm}$ to $\mathrm{H} 1$ in a single patient and without hyperleucocytosis. The search for scolex was not made on the operative parts for our patients. The indirect haemagglutination test is done in $87.5 \%$ of our patients came back negative. IFI is performed in a single patient of our series and negative income. The negative hydatid serology (ELISA) in our patients.

Standard radiography was performed in 7 of our patients, returning normal to 5 patients and 2 in favor of a soft tissue tumor without bone lesion or calcification.

In our series, all the patients underwent an ultrasound of soft parts showing a HH stage III GHARBI classification in $87.5 \%$ of patients and stage I in a single patient. An MRI was performed in all our patients to determine the number, size, topography, and relationships with the vasculoneural pedicles (Figure 6). Abdominal ultrasound and chest X-rays Returning with no particularity in all patients. In our series, all patients underwent surgical resection without breaking the shell, except in a single patient where the cyst was ruptured. Two patients required a supplement by medical treatment, the first operated for recurrence and the second after rupture of the cyst. The macroscopic appearance of hydatidosis is often typical at the opening of the operative specimen showing numerous vesicles and false membranes, which confirms the histological study. The average follow-up in our series is 27.5 months with a minimum of 12 months and a maximum of 5 years. All our patients had simple postoperative follow-up and they did not present any significant complications, and didn't present a recurrence so far.

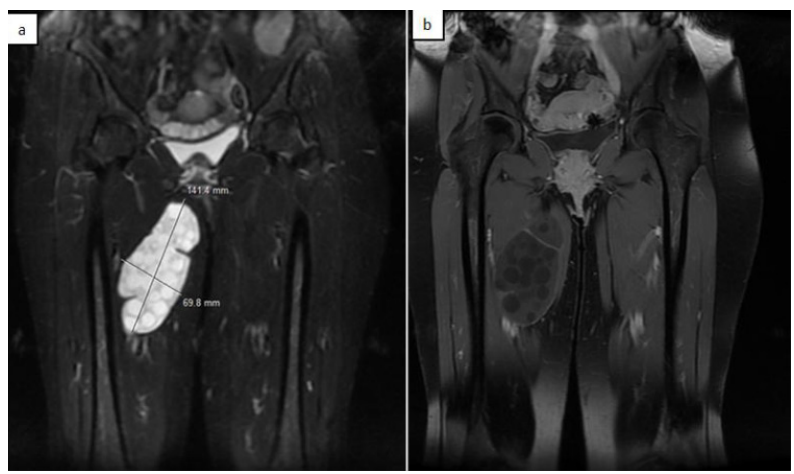

Figure 6 Hydatid cyst in TI hypointense and T2 hyperintense.

\section{Discussion}

From the epidemiological point of view, hydatidosis is a public health problem in the endemic areas represented by all livestock countries where dog-sheep contact is constant, especially around 
the Mediterranean, especially Morocco. Hydatidosis is prevalent in almost all rural areas of the country. Clinically, the symptomatology of soft tissue hydatidosis is nonspecific and often leads to diagnostic confusion with tumor pathology and often insidious after a long evolution, which explains the very high latency. It is usually a softtissue tumor with a very slow evolution. The hydatid cysts can be localized in all parts of the body, the hepatic localization is the most frequent followed by the pulmonary localization, the rarity Muscle localization can be explained by the passage of the parasite through two filters (hepatic and pulmonary) before reaching the great circulation. Muscle is an unfavorable environment for the development of the hydatid larvae because of muscular contractility on the one hand and the elaboration of lactate on the other hand.

The rupture of a cyst can lead to clinical manifestations of hypersensitivity such as fever, but also real anaphylactic shocks. Ultrasonography, CT and magnetic resonance imaging are a significant contribution to early positive diagnosis and provide essential radiological assessment before any surgical procedure. Imaging evokes the diagnosis during systematic examinations, establishes precisely the location, the size and the number of cysts and is part of the post-therapeutic surveillance. Biological examinations, serologies provide important diagnostic tools and monitoring of hydatidosis, it is based on the search for specific antibodies by quantitative techniques (indirect immunofluorescence, haemagglutination, ELISA) and qualitative (immunoelectrophoresis or Western Blot). ${ }^{8}$ A negative result never allows to exclude a hydatidose. Hyper eosinophilia may appear during cracking of the cystic wall. Hyperleukocytosis indicates bacterial surinfection of the cyst.

However the treatment of muscular hydatidosis still remains surgical. Total perkystectomy is the most effective treatment, with significant morbidity from conservative surgical treatment that needs to be emphasized. ${ }^{9}{ }^{10}$ Recent years have been marked by the development of percutaneous interventional radiology, such as aspiration-injection and re-aspiration (PAIR), and percutaneous drainage without re-aspiration, which have improved mortality and morbidity of patients. hydatid cysts. The results are encouraging, however the indications, the methods of use as well as the criteria and the evaluation times require a better definition on larger series. Complementary drug treatment is necessary to achieve a complete cure and avoid reinfections. ${ }^{11}$

\section{Conclusion}

The hydatid cyst of the soft parts is exceptional. The cyst can reach a very large volume. The treatment is surgical, but the best way to fight against hydatid disease, whatever its location, is prevention.

\section{Acknowledgements}

None.

\section{Conflicts of interest}

The authors declare no conflicts of interest.

\section{References}

1. Ambroise - Thomas P. Hydatidose-echinoccocose alvéolaire Maladies infectieuses EMC (paris). 4,1972-CD 8107

2. Bouree P, Gayral F. Diagnostic et traitement du kyste hydatique. EMC (paris). 7023, A10-6. 1982

3. S Bellil. Epidémiologie des kystes hydatiques extra pulmonaires: 265 cas en Tunisie, 2009

4. H Ghannane. Kyste hydatique chez l'enfant (6cas), 2009.

5. Memis A, Arkun R, Bilgen I, et al. Primary soft tissue hydatiddisease: reportoftwo cases with MRI characteristics. Eur Radiol. 1999;9(6):11011103.

6. Garcia-Diez AI, Ros Mendosa LH, Villa-campa VM, et al. MRI evaluation of soft tissue hydatiddisease. Eur Radiol. 2000;10(3):462466

7. Agoumi A. Précis de parasitologie médicale. Collection MEDIKA édition Horizons internationales. 2003:131-140.

8. Patrice B, Françoise B, Paula R. Immunologic diagnosis in parasitic disease in practice: benefit and limits. Revue Franoaise des Laboratoires. 2004;366:51-59.

9. Ben Jemaa M, Marrakchi C, Maaloul I, et al. Medical treatment of hydatid cysts: activity of albendazole in three patients (22 cysts). Médecine et maladies infictieuses. 2002;32:514-518.

10. Carpintero P, kindelan J, Montero R, et al. Hydatid cyst of spleen. J Clin Gastroenterol. 2001;33:89-90.

11. Chehab F, Khaiz D, Bouzidi A, La surveillence post opératoire du kyste hydatique du foie opéré. Médecine du Maghreb. 1997; 66:41-42. 